\title{
Region and Sex Differences in Constituent Dopamine Neurons and Immunoreactivity for Intracellular Estrogen and Androgen Receptors in Mesocortical Projections in Rats
}

\author{
Mary F. Kritzer and Lela M. Creutz \\ Department of Neurobiology and Behavior, Stony Brook University, Stony Brook, New York 11794-5230
}

\begin{abstract}
Many cortical and prefrontal functions show sex differences in their development, adult capacity, and dysfunction in disorders like schizophrenia. Correlations between circulating gonadal hormones and certain prefrontal functions have also been identified in humans and experimental animal models. Although multiple mechanisms may be involved, such hormone sensitivities/sex differences could be related to gonadal steroid actions on another regulator of cortical/prefrontal cortical function, the mesocortical dopamine system. Thus, although it is well known that perturbations in prefrontal dopamine signaling induce behavioral deficits, it is also known that several endpoints of these afferents are sensitive to gonadal steroids and/or are sexually dimorphic. This study explored possible substrates for this in two ways: by comparing the distributions of immunoreactivity for intracellular estrogen $(\alpha$ and $\beta)$ and androgen receptors among retrogradely labeled dopaminergic and nondopaminergic mesocortical neurons projecting to prefrontal, premotor, and primary motor cortices, areas in which male rat dopamine axons are differentially hormone-sensitive; and by comparing anatomical data in males and females. These analyses revealed region-, cell-, and sex-specific specializations in receptor localization that paralleled established patterns of mesocortical hormone sensitivity, including the androgen sensitivity of dopamine axons and dopamine-dependent functions in prefrontal cortex. It was also found that the proportions of dopamine neurons making up mesocortical projections were $\sim 30 \%$ in males, whereas in females, significantly more constituent cells were dopaminergic. Together, these features may be part of the neurobiology giving mesocortical afferents their hormone sensitivities and/or sex differences in physiology, function, and dysfunction in disease.
\end{abstract}

Key words: cognition; working memory; ventral tegmental area; testosterone; schizophrenia; substantia nigra pars compacta

\section{Introduction}

Many cortical functions including cognitive processes of the prefrontal areas show sex differences in development (Diamond, 1985; Clark and Goldman-Rakic, 1989; Bachevalier and Hagger, 1991; Overman et al., 1996), adult capacity (Einon, 1980; Tees et al., 1981; Hampson, 1990; van Haaren et al., 1990), and the incidence of their dysfunction in disorders including schizophrenia, autism, and attention deficit hyperactivity disorder (Goodman and Stevenson, 1989; Seeman and Lang, 1990; Leviton et al., 1993). Correlations between circulating gonadal hormone levels and performance in tasks measuring prefrontal processes such as working memory have also been identified in healthy humans and various patient populations of both sexes (Hampson, 1990; Gibbs and Gabor, 2003; Huber et al., 2005; Janowsky, 2006), and hormone manipulations in animal models have likewise been shown to impact performance in tasks measuring some of these same constructs (Ceccarelli et al., 2001; Daniel et al., 2003; Edinger et al., 2004; Frye et al., 2004; Gibbs, 2005; Kritzer et al.,

Received June 10, 2008; revised Aug. 5, 2008; accepted Aug. 5, 2008.

This work was supported by National Institutes of Health Grant NS-041996 to M.F.K. We thank Aiying Liu for expert assistance.

Correspondence should be addressed to Mary F. Kritzer, Department of Neurobiology and Behavior, Stony Brook University, Stony Brook, NY 11794-5230. E-mail: mkritzer@notes.cc.sunysb.edu.

DOI:10.1523/JNEUROSCI.2637-08.2008

Copyright $\odot 2008$ Society for Neuroscience $\quad$ 0270-6474/08/289525-11\$15.00/0
2007). The studies presented here asked whether such sex differences/hormone sensitivities might be related to gonadal steroid action on another potent regulator of prefrontal function, the mesocortical dopamine (DA) system. Thus, not only do perturbations in prefrontal DA neurotransmission significantly impair behavior (Kessler and Markowitsch, 1981; Murphy et al., 1996; Verma and Moghaddam, 1996; Zahrt et al., 1997), but numerous endpoints of this pivotal afferent system are influenced by gonadal hormones. In rats, for example, sex differences or hormone malleability have been demonstrated for prefrontal cortical DA axon density and in-growth, and for DA levels and turnover (Stewart and Rajabi, 1994; Kritzer, 2002; Dalla et al., 2008). However, little is known about where and how hormone sensitivity/ sex differences may be imprinted on mesocortical DA systems. Here, two approaches were taken to explore these issues. First, because immunoreactivity for intracellular estrogen $[\beta(\operatorname{ER} \beta)$ and $\alpha(\mathrm{ER} \alpha)$ ] and androgen receptors (ARs) have been localized to subsets of rat ventral midbrain DA neurons (Kritzer, 1997; Creutz and Kritzer, 2002), anatomical methods were used to determine precisely where these sites were found in relation to cortically projecting cells. Stimulated specifically by findings that gonadectomy in male rats increases DA axon density in medial prefrontal cortex in an androgen-sensitive manner, decreases DA axons in primary motor cortex in an estrogen-sensitive manner, and has no impact on DA innervation in premotor cortex 
(Kritzer, 2003), retrograde tracing was first used to label the mesocortical cells of origin of precisely these three pathways, and dual immunocytochemstry was used to identify their dopaminergic (DAergic) and intracellular hormone receptor (ER $\alpha, \mathrm{ER} \beta$, AR) phenotypes. Comparative analyses were subsequently used to look for parallels in the distributions of cognate receptors among mesocortical neurons projecting to cortical regions in which DA axons in males are sensitive to estrogen, androgen, and neither. Second, studies involved separate, comparative assessments of male and female subjects to obtain comprehensive information about male/female differences in the topography, neurochemistry, and hormone receptor immunoreactivity of cells of origin giving rise to afferent systems well known for sex differences in their physiology, function, and dysfunction in disease.

\section{Materials and Methods}

Animals. Data were collected from 12 adult male and 12 adult female Sprague Dawley (Taconic) rats $(200-300 \mathrm{~g})$. All procedures minimized animal use and their discomfort, and were approved by the Institutional Animal Care and Use Committee of Stony Brook University. Each animal received an injection of the retrograde tracer, cholera toxin (B subunit), conjugated to $7 \mathrm{~nm}$ colloidal gold (List Biological Laboratories), which was confined to the prelimbic (area PL, $n=4$ males, 4 females), premotor (area AGm, $n=4$ males, 4 females), or primary motor cortex (area AGl, $n=4$ males, 4 females) $8 \mathrm{~d}$ before euthanasia. Previous studies in adult male and adult female rats in diestrus and proestrus at the time of euthanasia revealed no apparent sex differences in ventral midbrain immunoreactivity for tyrosine hyroxylase (TH), ARs, or ER $\alpha$, or in their overlap, and only a slight decrease in immunoreactivity for ER $\beta$ in the diestrus compared with other groups (Kritzer, 1997; Creutz and Kritzer, 2002). Given this previous information about markers to be used here, other than avoiding the ovarian hormone nadir of metestrus, no other attempts were made to control for estrous cycle among female subjects.

Surgery. Craniotomies were performed under aseptic conditions using anesthesia consisting of intraperitoneal injections of ketamine and xylazine (90 mg/kg and $10 \mathrm{mg} / \mathrm{kg}$, respectively). Once anesthetized, rats were placed in a stereotaxic frame (David Kopf Instruments), a midline incision was made to expose the skull, and single burr holes were drilled at coordinates overlying cortical regions $\mathrm{PL}, \mathrm{AGm}$, or AGl in the right cerebral hemispheres (Donoghue and Wise, 1982; Van Eden and Uylings, 1985). Calibrated glass micropipettes containing the tracer were then lowered to calculated depths to reach the infragranular layers of the target cortical region, and $\sim 30 \mathrm{nl}$ of the solution was incrementally pressure injected over a $30 \mathrm{~min}$ period. Pipettes were left in place for an additional 15 min before being slowly withdrawn. Afterward, burr holes were packed with sterile gel foam and the incision was closed using prolene sutures.

Tissue preparation. Eight days after surgery, animals were deeply anesthetized with ketamine and xylazine $(150 \mathrm{mg} / \mathrm{kg}$ and $50 \mathrm{mg} / \mathrm{kg}$, respectively). After deep reflexes could no longer be elicited, the animals were perfused transcardially with a PBS flush, pH 7.4, followed by $800 \mathrm{ml}$ of 0.1 $\mathrm{M}$ phosphate buffer (PB), pH 7.4, containing 2\% paraformaldehyde and $15 \%$ picric acid. After perfusion, brains were removed, cryoprotected in $30 \%$ sucrose in $0.1 \mathrm{M} \mathrm{PB}$, and rapidly frozen in powdered dry ice before serial sectioning $(40 \mu \mathrm{m})$ on a freezing microtome.

Visualization of injection sites and retrograde labeling. Every third section through the frontal lobes was reacted to visualize the boundaries of injection sites, and separate one-in-six series of sections through the ventral midbrain were reacted to visualize retrogradely labeled cells, with and without immunocytochemical labeling (below). In all cases, the gold-conjugated cholera toxin tracer was revealed by a silver-plating reaction. For this, free-floating tissue sections were rinsed in $0.1 \mathrm{M} \mathrm{PB}, \mathrm{pH}$ 7.4 (four times for $15 \mathrm{~min}$ each), incubated in IntenSE silver enhancement solution (four times for 30 min each; GE Healthcare Life Sciences), rinsed again in $0.1 \mathrm{M} \mathrm{PB}$, and fixed in $2.5 \%$ sodium thiosulfate (10 min). Sections were then rinsed in $0.1 \mathrm{M} \mathrm{PB}$, slide-mounted, counterstained with $0.5 \%$ cresyl violet, dehydrated, and placed under coverslips.
Tracer visualization combined with immunocytochemistry. In one series of midbrain sections, only retrograde labeling was revealed. In three additional series of sections, double-label immunocytochemistry was used to coincidently identify hormone receptor (ER $\alpha$ or ER $\beta$ or AR) and neurochemical $(\mathrm{TH})$ phenotypes of the retrogradely labeled cells. The first step was silver enhancement of the tracer as above, but with the intensification procedure preceded by incubation of the sections in $1 \%$ $\mathrm{H}_{2} \mathrm{O}_{2}$ in $0.1 \mathrm{M} \mathrm{PB}$ (40 min). After silver intensification, the free-floating sections were immunolabeled as follows. First, sections were rinsed in TBS, pH 7.4 (three times for 15 min each), blocked in 10\% normal swine serum (NSS) in TBS [2 $\mathrm{h}$, room temperature (RT)], and placed in primary antisera diluted in TBS containing $1 \%$ NSS. Next, the sections were placed in antisera recognizing either ER $\alpha$ (rabbit polyclonal, Millipore. catalog no. 06-935, lot no. 18389; antigen-synthetic peptide, 15 amino acid C-terminal sequence of rat $\mathrm{ER} \alpha$, working dilution 1:6000), ER $\beta$ (rabbit polyclonal, Zymed Laboratories, catalog no. 51-7900, lot no. 01162952; antigen-synthetic peptide, 18 amino acid C-terminal sequence of mouse ER $\beta$, working dilution 1:1000), or ARs (rabbit polyclonal, Millipore, catalog no. 06-680, lot no. 33529; antigen-synthetic peptide, 21 amino acid N-terminal sequence of human ARs, working dilution $1: 1000)$. After incubations for $4 \mathrm{~d}$ in these primary antisera $\left(4^{\circ} \mathrm{C}\right)$, sections were rinsed in TBS and placed in biotinylated secondary antibodies (Vector Laboratories; $2 \mathrm{~h} ; 1: 100, \mathrm{RT}$ ). After rinsing again in TBS, sections were incubated in avidin-conjugated peroxidase solution [ABC (avidinbiotin complex) kit, Vector Laboratories; $2 \mathrm{~h}, \mathrm{RT}$ ) and rinsed again in TBS and then in TB. The tissue was then reacted using 3,3'diaminobenzidine (DAB)-nickel solution $(0.014 \%$ DAB and $0.6 \%$ nickel ammonium sulfate in TB, pH 8.0) as chromagen. After rinsing, the second immunolabeling protocol was performed next, as above, but using an overnight incubation in an anti-TH monoclonal antibody (Millipore Bioscience Research Reagents, catalog no. MAB 318, lot no. 23010512; antigen-TH purified from PC12 cells; working dilution 1:2000) and using $\mathrm{DAB}$ alone as chromagen. After processing, all sections were rinsed in TB, slide-mounted, dehydrated, and placed under coverslips.

Amplification steps were added for the labeling of ER $\beta$ immunoreactivity. First, sections were incubated in the primary antiserum, and then in goat anti-rabbit IgG secondary antiserum (Vector Laboratories; 12-16 $\mathrm{h}, 4^{\circ} \mathrm{C}, 1: 100$ ). The cholera toxin was then silver-plated (see above), after which the sections were incubated in a rabbit anti-goat secondary antisera (Vector Laboratories; $12-16 \mathrm{~h}, 4^{\circ} \mathrm{C}, 1: 100$ ), rinsed in TBS, and incubated in biotinylated goat anti-rabbit secondary antisera (Vector Laboratories; $2 \mathrm{~h}, 1: 100$ ). These sections were then rinsed (TBS), incubated in $\mathrm{ABC}$ solution, and reacted in DAB-nickel as above.

Antibody specificity and control experiments. All of the antibodies used were commercially available. Their selectivity was further evaluated in adult rat midbrain in immunolabeling protocols, both alone and in combination with silver intensification, that were performed on representative sections with the omission of the primary antisera and for anti-ER $\beta$ and anti-AR antibodies, using antisera that were preadsorbed (RT, $8 \mathrm{~h}$ ) with either $0 \mu \mathrm{g} / \mathrm{ml}, 0.01 \mu \mathrm{g} / \mathrm{ml}, 0.1 \mu \mathrm{g} / \mathrm{ml}$, or $1 \mu \mathrm{g} / \mathrm{ml}$ concentrations of the respective immunizing synthetic peptides [ARs, 20 amino acid $\mathrm{N}$ terminus of human AR (s.c.-816 blocking peptide), Santa Cruz Biotechnology; $\operatorname{ER} \beta, 18$ amino acid $C$ terminus of mouse $\operatorname{ER} \beta$, Zymed Laboratories (Creutz and Kritzer, 2002, 2004)], as well. Quantitative analyses previously performed in this laboratory have shown that the combined procedures used to achieve simultaneous labeling of tracer and multiple antigens does not appreciably attenuate $\mathrm{TH}$ or hormone receptor immunoreactivity or the detection of the gold-conjugated cholera toxin tracer (Creutz and Kritzer, 2004).

Case selection. Cortical regions were defined according to Donoghue and Wise (1982) and Van Eden and Uylings (1985). Confinement of injection sites to the desired cortical area was the first criterion used in case selection; this was confirmed using Nissl staining to identify cytoarchitectonic and laminar features and locations, and by examining patterns of retrograde labeling produced in the thalamus ipsilateral to the injection sites and in the cerebral cortex contralateral to them. Further selection criteria were that appropriately placed injection sites spanned both infragranular and supragranular cortical layers and produced similar minimum numbers of retrogradely labeled cells with visible nuclei 
per series of midbrain sections (see Figs. 1,2). Finally, all cases used in the analyses had to have patent immunostaining for TH, ER $\alpha, \mathrm{ER} \beta$, and ARs; to minimize potential for false negatives, only those cases in which immunoreactivity for each antigen of interest was robust, showed signal that was clearly discernable from background, and was distributed according to patterns of localization, colocalization, and apparent densities that were similar to what has been previously demonstrated and described for adult male and female rats (Kritzer, 1997; Creutz and Kritzer, 2002) were used.

Data analysis. All analyses were performed by a single observer (M.F.K.). In each subject, the distributions of retrogradely labeled cell populations were mapped from a one-in-six series of midbrain sections using a Zeiss Axioskop microscope, a camera lucida, and combinations of bright- and dark-field optics and low- to higher-power objectives $(10-40 \times)$. In additional series of sections, retrogradely labeled cells that were and were not immunoreactive for $\mathrm{TH}$, and that were and were not immunoreactive for $\mathrm{ER} \alpha, \mathrm{ER} \beta$, or ARs and/or for $\mathrm{TH}$ were similarly mapped under bright-field optics; in these, higher-power objectives $(40 \times, 63 \times)$ and roll-focusing was used to verify the coincidence of labels in individual cells. Uncorrected counts were subsequently made of all visible singly, doubly, and triply labeled subpopulations of cells present in a given section meeting inclusion criteria of having visible nuclei on per structure and per section bases. Because of the potential for overestimations in uncorrected cell counts (Guillery, 2002), the numbers of cells that were counted by these means were used only to assure that, across cases, the injection sites evaluated produced sufficient and similar numbers of labeled midbrain cells (Figs. 1,2). All quantitative comparisons of the data across groups used percentages of all visible cells that were made up by a given subclass of cells; assessments of descriptive statistics were followed by nonparametric analyses using the MannWhitney/Wilcoxon rank sum test (StatView), where $p<0.05$ levels were accepted as significant.

Photography. The digital photomicrographs presented were taken using a Zeiss Axiocam and a Zeiss Axioplan 2 microscope; some adjustments to image brightness and contrast have been made using Zeiss Axiovision or Canvas 8.0 software.

\section{Results}

\section{Appearance and locations of injection sites}

Cortical injection sites appeared as dense foci of uniformly black reaction product (Fig. $3 A, B, D, E, G, H$ ). Camera lucida reconstructions that mapped the boundaries of injection sites in relation to cortical cytoarchitecture (males, Fig. 1; females, Fig. 2) showed that for areas PL, AGm, and AGl alike, all sites selected for analysis were appropriately localized and were well matched for size and for anteroposterior, dorsoventral, and laminar location. The localization of injection sites to area PL was further confirmed by the production of expected patterns of dense labeling in the medial division of the mediodorsal nucleus of the thalamus ipsilaterally and in homotypic portions of area PL contralaterally (Heidbreder and Groenewegen, 2003). Injections in area AGm were verified by the dense labeling produced in the lateral mediodorsal, the central lateral, and the inter-anteromedial nucleus of the thalamus ispsilateral to the injection site (Hicks and Huerta, 1991; Reep and Corwin, 1999), and in contralateral portions of rostral area AGm (Reep et al., 1990); and area AGl injections were confirmed by the dense labeling that was produced in the ipsilateral ventrolateral nucleus of the thalamus (Donoghue and Parham, 1983; Aldes, 1988; Condé et al., 1990), and the contralateral homotypic region of the rostral primary motor field (Donoghue and Parham, 1983).

\section{Retrograde cell labeling and co-immunoreactivity}

Retrogradely labeled ventral midbrain neurons were identified by the presence of above-background levels of silver grains in their somata and proximal processes (Fig. 4). The morphology dis- cernable in these cells was consistent with existing descriptions of neurons found in the various nuclei of the rat ventral midbrain (Moore and Bloom, 1978; Phillipson, 1979). For example, labeled cells in the intrafascicular nucleus (IF) (Fig. $4 \mathrm{~J}$ ) tended to be small and of simple, rounded geometry, whereas those found in the paranigral VTA (PN-VTA) (Fig. $4 K-N$ ) and the rostral (rostrolinear) (RLi) and caudal linear nuclei (CLi) (Fig. 4I) were often small and more fusiform in shape. Those present in the parabrachial VTA (PBP) and substantia nigra, pars compacta ( $\mathrm{SNpc}$ ), however, tended to be larger, and generally more complex and multipolar in morphology (Fig. 4Q,P).

In sections in which transmitter and hormone receptor phenotypes were co-identified, presumed DAergic cells were identified by brown cytoplasmic DAB reaction product marking immunoreactivity for the dopamine-synthesizing enzyme, TH (e.g., Fig. $4 A, B, D$ ), and immunoreactivity for $\operatorname{ER} \alpha, \mathrm{ER} \beta$, or AR proteins (Fig. $4 E-H$ ) was revealed by blue-black DAB/nickel reaction product localized to the cell nuclei. Back-labeled ventral midbrain neurons that were singly (Fig. $4 A, C, F$ ), doubly (Fig. $4 B, D, E$ ), or triply (Fig. $4 G, H$ ) labeled by these methods were readily distinguishable, and the coincidence of labels within the same cell was verifiable using high-power objectives and roll focusing. As anticipated in previous studies (Kritzer, 1997; Creutz and Kritzer, 2002), all cases, regardless of sex, had similar distributions of TH and hormone receptor immunoreactivities as well as degrees of overlap between the two.

\section{Retrograde labeling from area PL, AGm, and AGl injections}

Labeling from four male and four female subjects with injection sites confined to medial prefrontal cortical area PL (Figs. $1 A, 2 A$ ), four of each sex with injections in area AGm (Figs. $1 B, 2 B$ ), and four per sex with injections localized to area AGl (Figs. $1 C, 2 C$ ) was evaluated. The distributions and apparent densities of the ventral midbrain cells retrogradely labeled by all of these injections were similar for all of the within-group cases (injection sites in the same cortical area) in males and females alike.

After area PL injections, ventral midbrain labeling was sparse and located mainly within the ventral-most VTA ipsilateral to the injection site (Fig. 5A). More than half of all of the labeled cells were found in the ventral half of the PN-VTA (Figs. $4 L, 5 A$ ), approximately one-fourth of the cells were found along the ventral edge of the rostromedial PBP (Figs. $4 N, 5 A$ ), and a little less than one quarter were found in ventral portions of the IF nucleus (Figs. $4 J$, 5A). Smaller numbers of labeled cells were also found scattered within more dorsal parts of the ipsilateral VTA, the RLi nucleus, and the contralateral VTA (Fig. 5A). The ventral midbrain labeling produced from area AGm injections was noticeably sparser than that produced by the area PL sites, with most of the labeled cells found ipsilaterally and scattered in mid to dorsal aspects of the PN-VTA (Figs. $4 K, 5 B$ ) and adjacent portions of the PBP (Figs. $4 M, 5 B$ ). Smaller numbers of labeled cells also spread from the PBP into the medial SNpc, into the IF and RLi nuclei, and more rarely across the midline into the contralateral VTA (Fig. 5B). Finally, the midbrain labeling produced by area AGl injections was also sparse and located primarily ipsilaterally (Fig. $5 C)$. Although labeling included small numbers of cells within the dorsal midline nuclei (RLi and CLi, Figs. 4I, 5C) and a very few cells scattered within the PN-VTA, most of the labeling was located in mid to dorsal aspects of the $\mathrm{PBP}$ and in the laterally adjacent SNpc (Figs. 4O,Q,R, 5C). 
MALES

\section{A Area PL Injection sites, $n=4$}

Labeled midbrain cells:
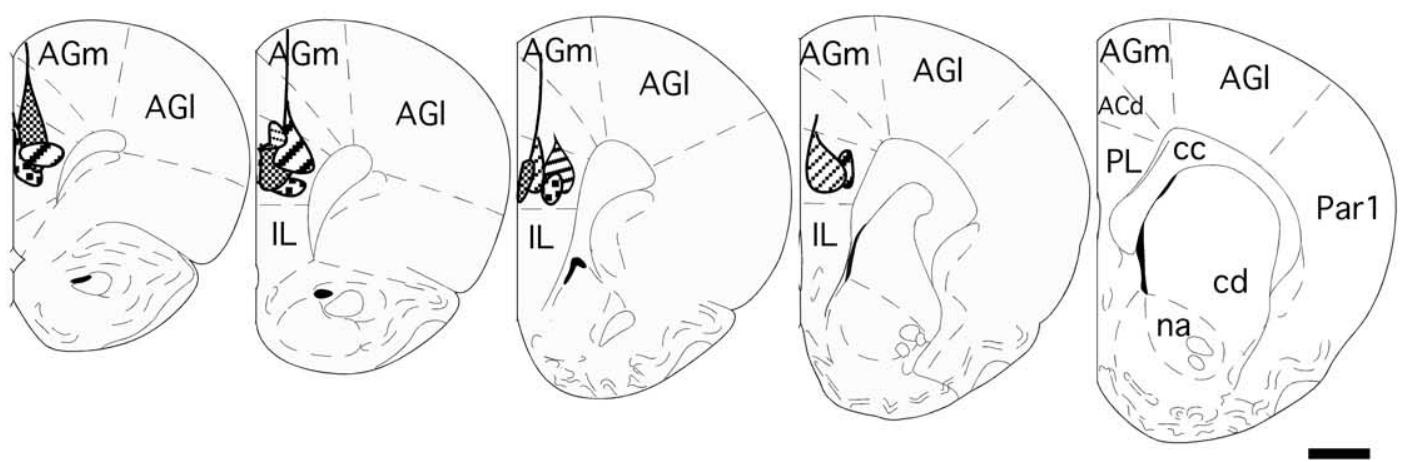

Visible cells per series

(average \pm SEM)

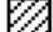

$71.25+2.17$

兴 $87.5 \pm 3.07$

ש $59.50 \pm 4.22$

B $90.5+9.86$

\section{B Area AGm Injection sites, $\mathrm{n}=4$}

Labeled midbrain cells
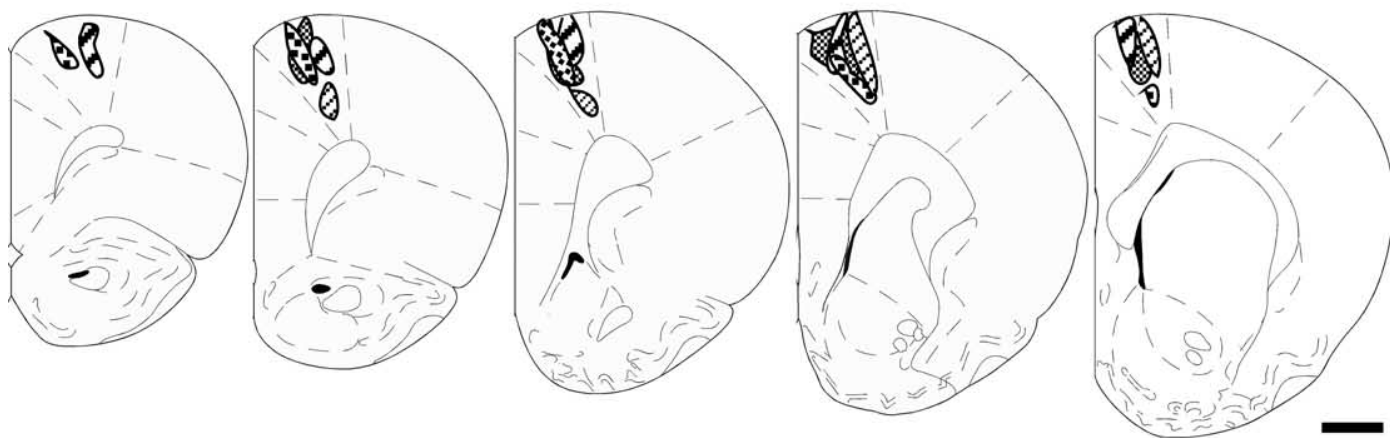

visible per series

(average \pm SEM)

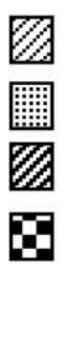

$30.22 \pm 4.57$

$45.37 \pm 3.96$

$44.11 \pm 6.13$

$22.30+1.19$

\section{Area AGI Injection sites, $n=4$}

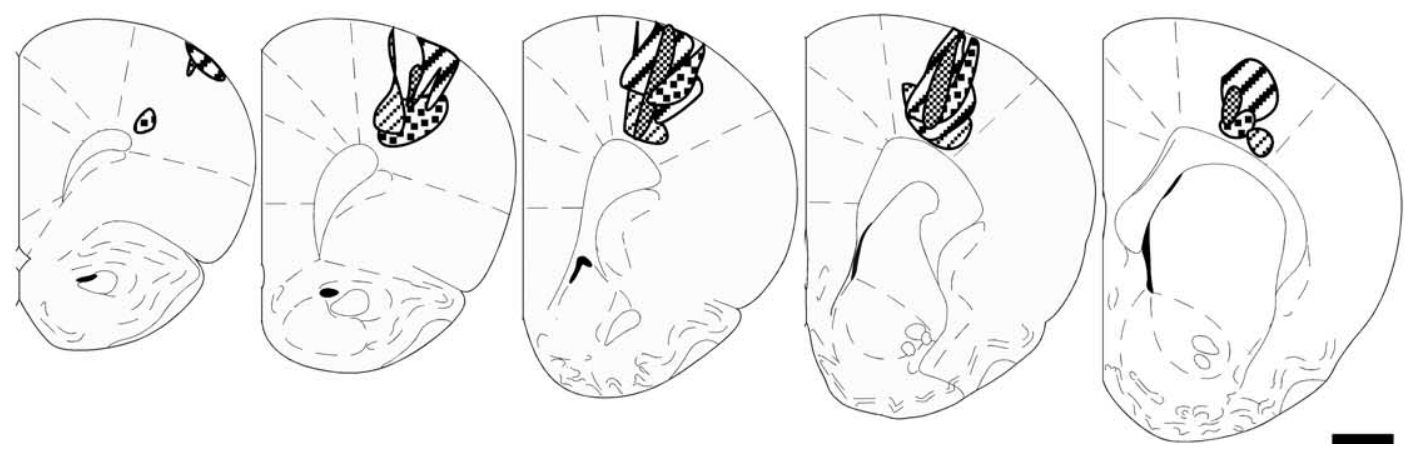

Labeled midbrain cells visible per series (average \pm SEM)

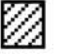

$67.37+3.11$

$80.89 \pm 5.43$

$89.09 \pm 6.07$

$68.77 \pm 1.98$

Figure 1. A-C, Schematic drawings showing the locations of all injection sites evaluated in the male subjects of this study. Grayscale patterns identify the boundaries of the four injection sites in medial prefrontal area $\mathrm{PL}(\boldsymbol{A})$, in the premotor cortex area $\mathrm{AGm}(\boldsymbol{B})$, and in the primary motor cortex area $\mathrm{AGI}(\boldsymbol{C})$ that were made in the individual subjects. The corresponding values on the right are mean numbers of all visible, retrogradely labeled cells observed in the midline nuclei, the ventral tegmental area, and the substantia nigra meeting inclusion criteria of having visible nuclei counted in separate one-in-six series of ventral midbrain tissue sections; the errors shown are SEM. Section outlines are adapted from the atlas of Paxinos and Watson (1998). Scale bars, $1 \mathrm{~mm}$. IL, Infralimbic cortex; ACd, anterior cingulate cortex; Par1, primary somatosensory cortex; cc, corpus callosum; cd, caudate nucleus; na, nucleus accumbens.

Proportions of retrogradely labeled TH-IR cells

For injection sites in all three cortical regions evaluated, visual inspection alone revealed that back-labeled cells that were TH-IR comprised a minority of the retrograde labeling in males and noticeably more back-labeled cells in females. Quantitative assessments of the proportions of all back-labeled cells that were TH-IR and TH-immunonegative that were made on case-by-case bases corroborated these observations. For area PL injections, back-labeled cells that were TH-IR comprised between 18 and $43 \%(30.50 \pm 5.29$, mean \pm SEM $)$ of all retrogradely labeled cells in males, and $>50 \%(54.00 \pm 1.00)$ in three of the four females evaluated (Fig. 6A). For area AGm injections, fewer than one in five retrogradely labeled cells $(17.25 \pm 2.75 \%)$ were TH-IR in males, whereas in females, nearly half $(46.50 \pm 2.96)$ of all visible back-labeled cells were TH-IR (Fig. 6B). In addition, after area AGl injections, approximately one-third of all retrogradely labeled cells $(32.75 \pm 2.69)$ were TH-IR in males, whereas in females, significantly higher proportions of all visible backlabeled cells were immunoreactive for this synthetic enzyme (Fig. 6C, $49.00 \pm 1.732$ ). Statistical comparisons (MannWhitney/Wilcoxon rank sum test) of all of these data showed further that, for all three cortical regions assessed, the propor- 
FEMALES

A Area PL Injection sites, $\mathrm{n}=4$

Labeled midbrain cells:

Visible cells per series


(average \pm SEM)

\section{B Area AGm Injection sites, $n=4$}
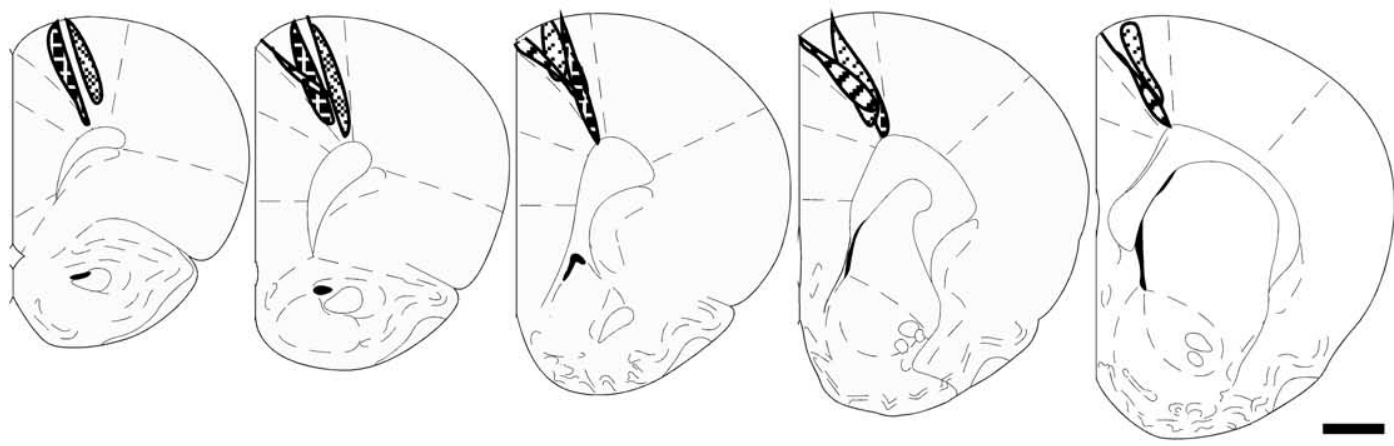

Labeled midbrain cells visible per series (average \pm SEM)

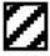

$35.33+3.22$

曲

$48.00 \pm 1.36$

$30.28+2.35$

$34.00 \pm 1.05$

\section{Area AGI Injection sites, $n=4$}

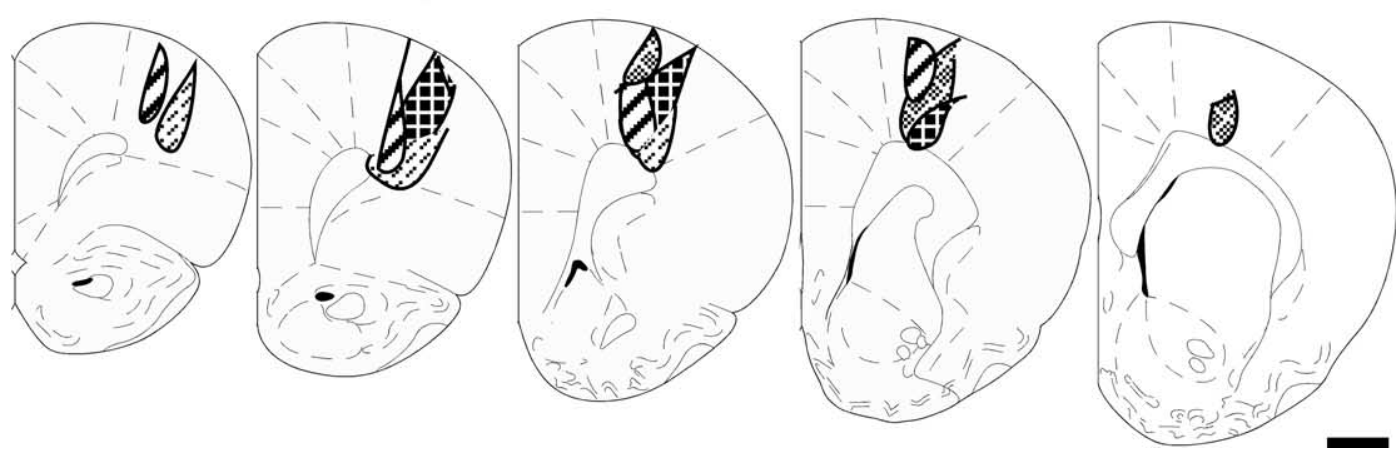

Labeled midbrain cells visible per series (average \pm SEM)

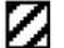

$27.01 \pm 0.05$

囲 $37.00 \pm 2.21$

国

$28.24 \pm 1.98$

图

$28.67+3.74$

Figure 2. A-C, Schematic drawings showing the locations of all injection sites evaluated in the female subjects of this study. Grayscale patterns identify the boundaries of the four injection sites in medial prefrontal area $\mathrm{PL}(\boldsymbol{A})$, in the premotor cortex area $\mathrm{AGm}(\boldsymbol{B})$, and in the primary motor cortex area $\mathrm{AGI}(\boldsymbol{C})$ that were made in the individual subjects. The corresponding values on the right are mean numbers of all visible retrogradely labeled cells observed in the midline nuclei, the ventral tegmental area, and the substantia nigra meeting inclusion criteria of having visible nuclei counted in separate one-in-six series of ventral midbrain tissue sections; the errors shown are SEM. Section outlines are adapted from the atlas of Paxinos and Watson (1998). Scale bars, $1 \mathrm{~mm}$. IL, Infralimbic cortex; ACd, anterior cingulate cortex; Par1, primary somatosensory cortex; cc, corpus callosum; cd, caudate nucleus; na, nucleus accumbens.

tions of retrogradely labeled projection cells that were TH-IR in females were non-overlapping with, and significantly higher than those in males (Mann-Whitney $U=0$; Wilcoxon rank $=10 ; p<0.03$, Fig. 6).

Intracellular hormone receptor immunoreactivity within TH-IR cells

In females, retrogradely labeled TH-IR cells that were also immunoreactive for intracellular hormone receptors were limited mainly to small fractions $(3.54 \pm 1.299 \%)$ of TH-IR cells backlabeled by area $\mathrm{Pl}$ injections that were AR-IR (Fig. 7A); there were also a few individual examples of back-labeled TH-IR cells in one area PL-injected case that were ER $\beta$-IR and none that were ER $\alpha$-IR (Fig. 7A). In males, significantly more TH-IR cells backlabeled by area PL injections were AR-IR $\left(25.75 \pm 6.799 \%, F_{(1,6)}\right.$ $=10.29, p<0.018)$. Further, an additional $2-17 \%(6.40 \pm 3.17)$ of the area PL-labeled TH-IR cells were ER $\beta$-IR, and none were ER $\alpha$-IR (Fig. 7A). For area AGm injections, no overlap was observed in any of the cases, male or female, between back-labeled TH-IR cells and immunoreactivity for $\mathrm{AR}, \mathrm{ER} \alpha$, or $\mathrm{ER} \beta$ (Fig. $7 B$ ). Finally, after area AGl injections, in males nearly 30\% (27.75 \pm 7.87 ) of the back-labeled TH-IR cells observed were also ER $\beta$-IR, 
lower and more variable proportions $(0-$ $14 \%, 5.00 \pm 3.32)$ were AR-IR, and none were ER $\alpha$-IR (Fig. 7C). That there was no overlap observed between any TH-IR cells back-labeled by area AGl injections and hormone receptor immunoreactivity in females (Fig. $7 C$ ) yielded a significant sex difference among the TH/ER $\beta$-IR cells (Mann-Whitney $U=0$; Wilcoxon rank $=$ $10 ; p<0.03)$. It should be emphasized that in the all of the instances of negative findings (where there was no overlap between labeling and immunoreactivity) above, as well as all that are described below, it was invariably the case that hormone receptorimmunoreactive cells were present among cells that were retrogradely labeled, but that the two populations simply did not coincide.

\section{Intracellular hormone receptor immunoreactivity within TH-immunonegative cells}

In males and females alike, retrogradely labeled, TH-immunonegative cells produced by injection sites in all three cortical areas evaluated showed the greatest, most consistent, and largely similar degrees of overlap with immunoreactivity for AR (Fig. 8). Across all areas, back-labeled THimmunonegative cells that were AR-IR corresponded to as much as one third of all such cells in males (area PL, $30.28 \pm$ $4.80 \%$, Fig. $8 A$; area AGm, $15.5 \pm 2.28$, Fig. $8 B$; area AGl, $35.33 \pm 2.63$, Fig. $8 C$ ) and, on average, some $10-25 \%$ of all such cells in females (area PL, $25.75 \pm 3.74$, Fig. $8 \mathrm{~A}$; area AGm, $22.72 \pm 2.26$, Fig. $8 \mathrm{~B}$; area AGl, $9.42 \pm 7.09$, Fig. $8 C$ ). By comparison, there was relatively little, typically more variable and sex-specific, and in several instances, no coincidence whatsoever between retrograde labeled $\mathrm{TH}$-immunonegative neurons and immunoreactivity for $\mathrm{ER} \alpha$ and/or for $\mathrm{ER} \beta$. In males, none of the retrogradely labeled $\mathrm{TH}$-immunonegative cells produced by injection sites in any of the three cortical areas were immunoreactive for $\mathrm{ER} \alpha$ (Fig. 8 ), none produced by area AGm injections were ER $\beta$-IR (Fig. $8 B$ ), and only some $5-10 \%$ of all TH-immunonegative cells retrogradely labeled by area PL (Fig. $8 \mathrm{~A}$ ) and AGl injections were ER $\beta$-IR (Fig. $8 C$ ). In females, a very different pattern was observed in which there was a consistent, albeit small, degree of overlap observed between retrogradely labeled $\mathrm{TH}$ immunoegative cells and immunoreactivity for $\mathrm{ER} \alpha$ (area $\mathrm{Pl}$, $4.00 \pm 0.97$, Fig. 8 A; area AGm, $4.32 \pm 1.74$, Fig. $8 B$; area AGl, $5.71 \pm 3.92$, Fig. $8 C$ ), but no overlap between back-labeling from any injection site and immunoreactivity for $\operatorname{ER} \beta$. Nonparametric analyses that separately compared these doubly labeled cell populations revealed that only in two cases, and in both instances compared with there being no such cells in the males, were the modest proportions of TH-immunonegative, ER $\alpha$-IR cells found in females non-overlapping with and significantly greater than those in males (area PL, Fig. $8 A$; area AGm, Fig. $8 B$; MannWhitney $U=0$; Wilcoxon $\operatorname{rank}=10$; $p<0.03$ ].

\section{Discussion}

The clinical and basic science literature includes examples of often sex-specific hormone stimulation of mesocortical DA systems and the cortical functions they influence. This study explored possible substrates for these by comparing the distributions of immunoreactivity for $\mathrm{AR}, \operatorname{ER} \alpha$, and $\operatorname{ER} \beta$ among midbrain DAergic and non-DAergic neurons projecting to cortical areas that are differentially hormone-sensitive in male rats, and by comparing anatomical details in male and female subjects. These analyses revealed new information about mesocortical organization in rats including that for two previously unexplored areas. Whereas sex differences in overall connectivity were not apparent, functionally suggestive region-, sex-, and cell-specific deployments of intracellular hormone receptor immunoreactivity among constituent mesocortical neurons were observed. For example, in males, regional differences in ER and AR distribution matched the differing sensitivities of DA axons in the injected areas to gonadectomy and hormone replacement. Further, in males and females, meso-prefrontal DA neurons were the most strongly aligned with immunoreactivity for AR, which is consistent with the androgen sensitivity and estrogen insensitivity demonstrated for specific prefrontal functions. What was 


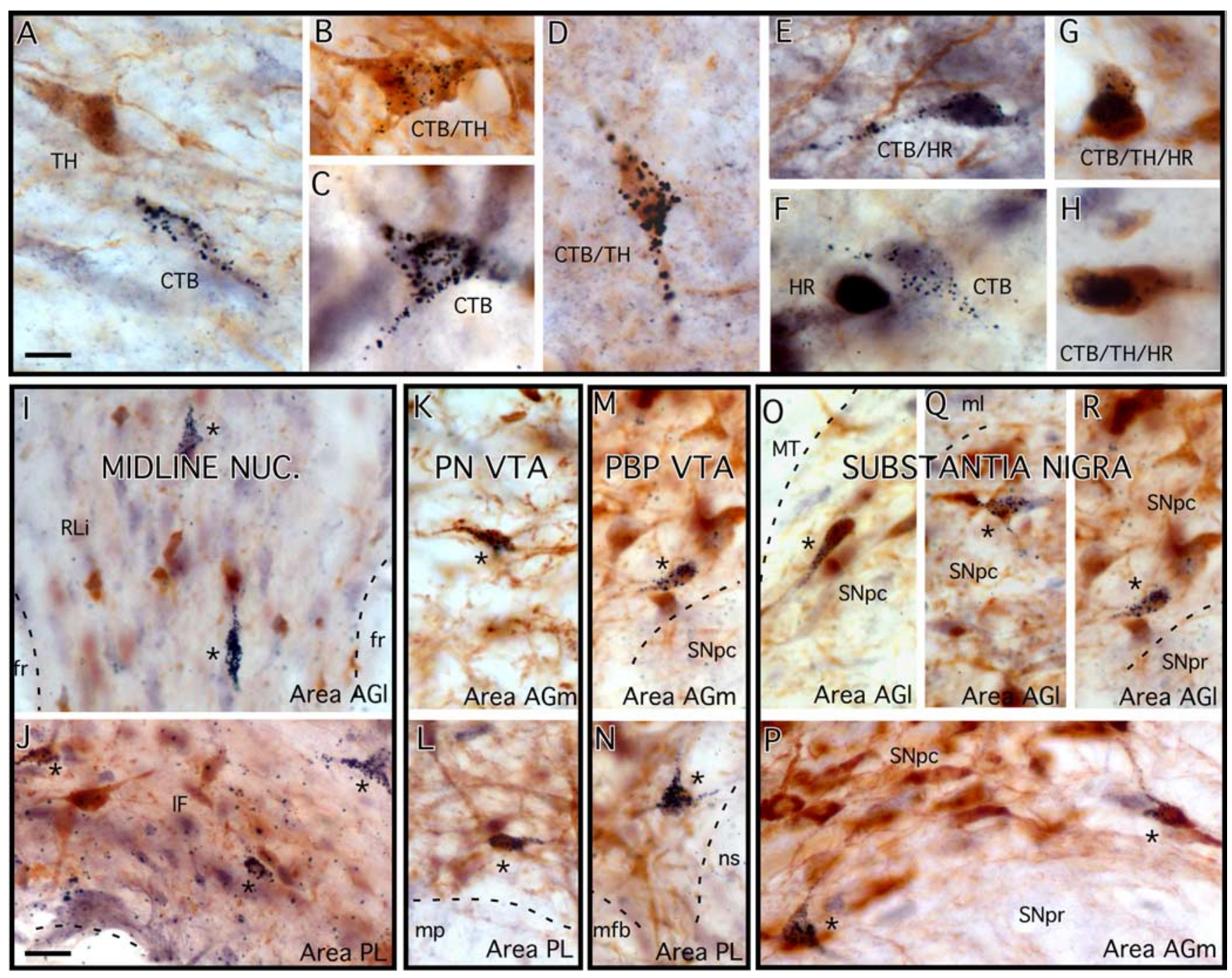

Figure 4. $\quad \boldsymbol{A}-\boldsymbol{H}$, High-power color photomicrographs showing the appearance of representative ventral midbrain neurons retrogradely labeled by cortical injections of cholera toxin (CTB) ( $A, C$ ) immunoreactive for TH $(\mathbf{A})$, immunoreactive for intracellular hormone receptors $(H R)(\boldsymbol{F})$, and doubly $(\boldsymbol{B}, \boldsymbol{D}, \boldsymbol{E})$ and triply $(\boldsymbol{G}, \boldsymbol{H})$ labeled by these markers. Retrograde labeling is identified by the presence of silver-enhanced gold particle grains in cell somata and proximal processes, TH immunoreactivity is marked by brown, cytoplasmic reaction product, and hormone receptor immunoreactivity appears as blue-black reaction product over cell nuclei. The cells appearing in $\boldsymbol{E}, \boldsymbol{G}$, and $\boldsymbol{H}$ are immunoreactive for AR, ER $\boldsymbol{\beta}$, and ER $\alpha$, respectively. $\boldsymbol{I}-\boldsymbol{R}$, Lower-power photomicrographs showing the differential, characteristic, medial-to-lateral and ventral-to-dorsal distributions of cells in the midline nuclei $(I, J)$, the PN-VTA $(K, L)$, the PBPVTA $(M, N)$, and the substantia nigra $(0-R)$ retrogradely labeled by $C T B$ injections in area $\mathrm{PL}(\boldsymbol{J}, \boldsymbol{L}, \boldsymbol{M})$, and area $\mathrm{AGm}(\boldsymbol{K}, \boldsymbol{M}, \boldsymbol{P})$ versus area $\mathrm{AGI}(\boldsymbol{O}, \boldsymbol{Q}, \boldsymbol{R}) . \boldsymbol{A}, \boldsymbol{B}, \boldsymbol{C}, \boldsymbol{F}, \boldsymbol{H}, \boldsymbol{J}, \boldsymbol{K}, \boldsymbol{M}, \boldsymbol{N}, \boldsymbol{P}$, Labeling from female cases; $\boldsymbol{D}, \boldsymbol{E}, \boldsymbol{I}, \boldsymbol{L}, \mathbf{O}, \boldsymbol{Q}, \boldsymbol{R}$, labeling from male subjects. fr, Fasciculus retroflexus; ML, medial lemniscus; mp, mammillary peduncle; mfb, medial forebrain bundle; ns, nigrostriatal bundle; SNpr, substantia nigra, pars reticulata. Scale bar: (in $A$ ) $\boldsymbol{A}-\boldsymbol{H}, 10 \mu \mathrm{m} ;$ (in $\boldsymbol{J}) \boldsymbol{I}-\boldsymbol{R}, 20 \mu \mathrm{m}$.

most surprising, however, was the discovery of an unexpected and unexpectedly large sex difference in the proportions of DAergic neurons making up all three mesocortical pathways examined.

\section{Mesocortical organization in rats}

Retrograde labeling produced by area PL injections was similar to that reported previously (Lindvall et al., 1978; Swanson, 1982; Loughlin and Fallon, 1984; Deutch et al., 1991; Ohara et al., 2003), with all studies reporting abundant labeling in midline nuclei and the PBP and PN-VTA. Together with previous studies of insular, entorhinal, and piriform cortices (Datiche and Cattarelli, 1996; Ohara et al., 2003), the current assessments of premotor and primary motor areas essentially complete analyses of mesocortical projections to the DA-enriched portions of rat cortex. The data collectively support consensus views of anatomical overlap and subtle mediolateral topogra- phy among mesocortical cells projecting to disparate cortical fields. Thus, although all injections here labeled the midline and VTA, labeling was increasingly centered on more lateral portions of the VTA to medial SNpc for area Pl to AGm to AGl injections. Further, a dorsoventral topography was also discerned wherein labeling produced by area PL injections was concentrated in the ventral PN-VTA, that produced by area AGm sites was centered more dorsally in the PN-VTA, and that produced by area AGl injections was focused more dorsally still within the PBP. Although dorsoventral shifts in labeling are seen for cortical injections differing in anteroposterior location (Loughlin and Fallon, 1984), the injections in this study were all placed at similar rostrocaudal levels. Thus, the dorsoventral gradient observed here appears to be an additional facet of organization, suggesting in turn that mesocortical projections in rats are governed by multiple sets of subtle topographic rules. 


\section{Hormone receptor immunoreactivity in} mesocortical neurons

Gonadectomy in adult male rats decreases DA axon density in primary motor cortex in an estrogen-sensitive manner, increases axon density in medial prefrontal cortex in an androgen-sensitive way, but has no effect on innervation in premotor cortex (Kritzer, 2003). Here, parallels with all of these data were found in male rats in the predominance of $\mathrm{ER} \beta$ and AR immunoreactivity among DAergic projections to areas $\mathrm{AGl}$ and $\mathrm{Pl}$, respectively, and in the absence of receptor immunoreactivity among DAergic projections to area AGm. Because effects of gonadectomy on prefrontal DA axons have been correlated with those on DA-dependent prefrontal functions (Kritzer et al., 2007), these findings not only implicate genomic mechanisms in the influence over DA axon arbors, but identify them as potentially relevant for the hormone sensitivity of cortical, especially prefrontal cortical, functions as well.

The data also identify androgenstimulated events as probable predominant forms of genomic influence over meso-prefrontal systems, because AR immunoreactivity in both sexes was found in area PL-projecting DA neurons in excess or to the exclusion of immunoreactivity for $\mathrm{ER} \alpha$ and $\mathrm{ER} \beta$. This is consistent with the androgen sensitivity of DA-dependent meso-prefrontal functions demonstrated in male rats, in which gonadectomyinduced impairments of operant spatial working memory, T-maze acquisition, and novel object recognition have all been shown to be attenuated by testosterone but not estradiol (Kritzer et al., 2001, 2007; Aubele et al., 2008), and with data in humans showing correlations between performance of prefrontal tasks and circulating testosterone levels in healthy men, and in clinical cases of hypogonadism (Alexander et al., 1998; Cherrier et al., 2003; Salminen et al., 2003, 2005) and schizophrenia (Shirayama et al., 2002; Goyal et al., 2004; Taherianfard and Shariaty, 2004; Huber et al., 2005; Akhondzadeh et al., 2006). Correlations in adult women between serum testosterone and certain spatial and mnemonic tasks (Gouchie and Kimura, 1991; Postma et al., 2000; Aleman et al., 2004) also suggest that androgens also influence prefrontal function in this sex. Although questions remain, the cognitive deficits observed in disorders in which testosterone levels in women are abnormally high or low, e.g., congenital adrenal hyperplasia (Puts et al., 2008), polycystic ovary syndrome (Schattmann and
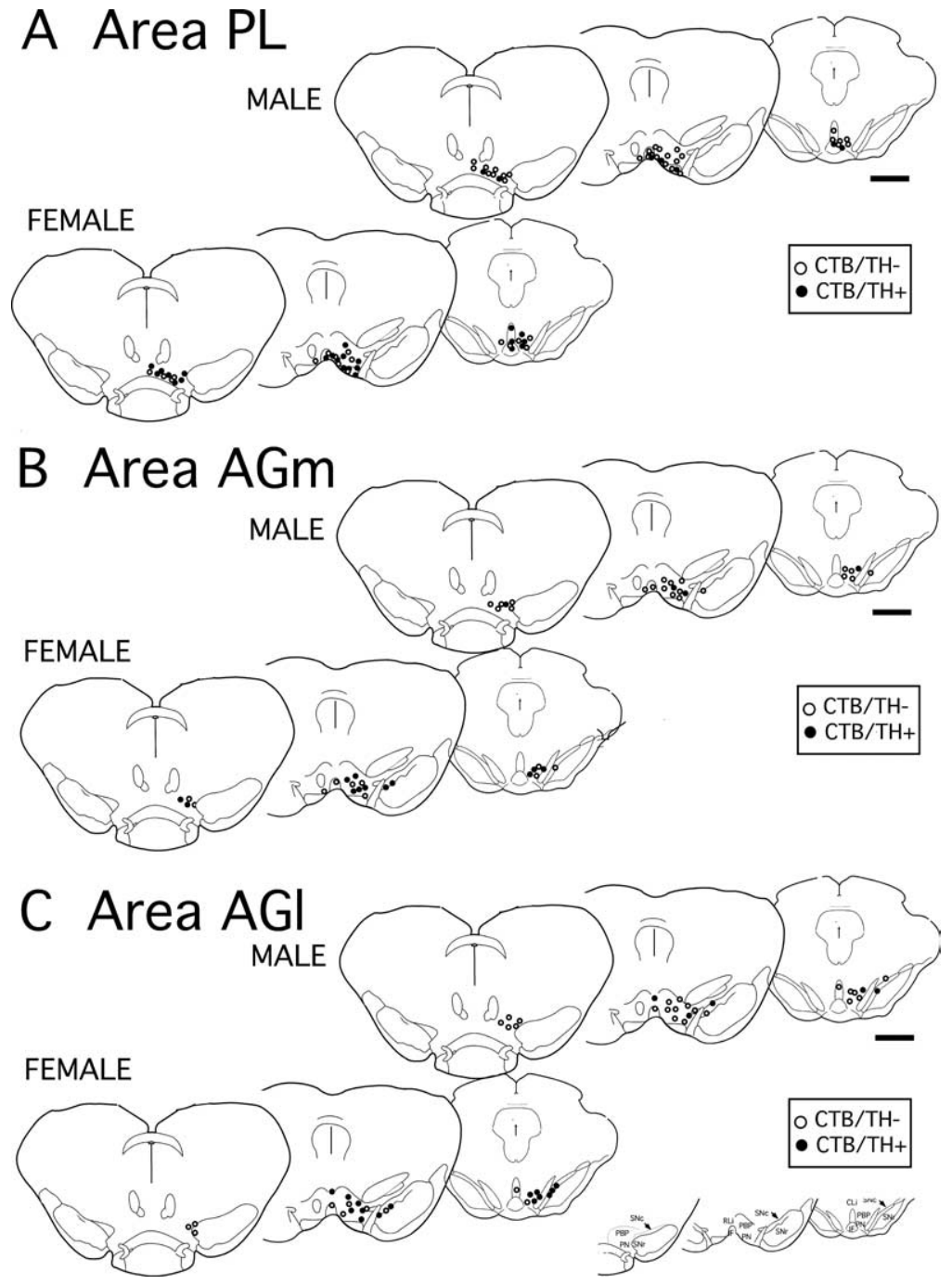

Figure 5. $\quad A-C$, Plots adapted from camera lucida drawings from a representative case showing locations of ventral midbrain neurons retrogradely labeled by cholera toxin (CTB) injections localized to cortical area PL $(\boldsymbol{A})$, area AGm (B), and area AGI (C). For each, labeling from one male and one female case is shown as marked, retrogradely labeled cells that were immunoreactive for tyrosine hydroxylase $(\mathrm{TH}+)$ are shown as black circles $(\mathrm{CTB} / \mathrm{TH}+)$, those that were $\mathrm{TH}$ immunonegative $(\mathrm{TH}-)$ are shown as open circles, and an anatomical key is included for reference. The localization of labeling in the ventral midline and PN-VTA produced by area PL injections $(\boldsymbol{A})$ contrasts with the more diffuse and more laterally and dorsally located foci of labeling produced for injections in areas AGm (B) and AGI (C). Scale bars, $1 \mathrm{~mm}$. SuM, Supramammillary nucleus; IF, interfascicular nucleus; SNr, substantia nigra, pars reticulata; $\mathrm{SNc}$, substantia nigra, pars compacta; Cli, caudolinear nucleus.
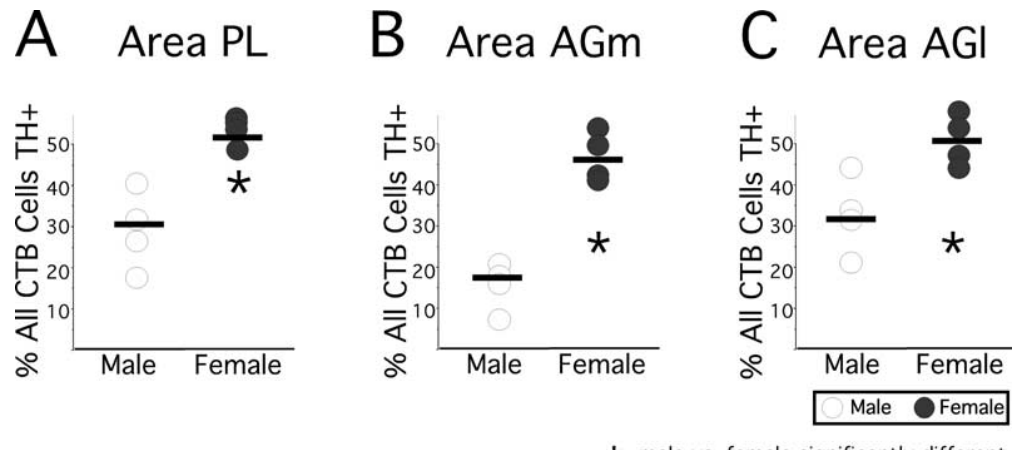

* male vs. female significantly different

Figure 6. A-C, Scatter plots showing percentages of all visible cells that were retrogradely labeled by cholera toxin (CTB) injections made in area PL $(\boldsymbol{A}), \mathrm{AGm}(\boldsymbol{B})$, and $\mathrm{AGI}(\boldsymbol{C})$ that were also immunoreactive for tyrosine hydroxylase $(\mathrm{TH}+)$. Data points from each of the four male (open circles) and four female (black circles) subjects evaluated are shown, and group means are marked by horizontal black bars. Asterisks identify cases in which Mann-Whitney/Wilcoxon rank sum tests identified significant differences in the proportions of retrogradely labeled cells that were TH-immunopositive between males and females. 

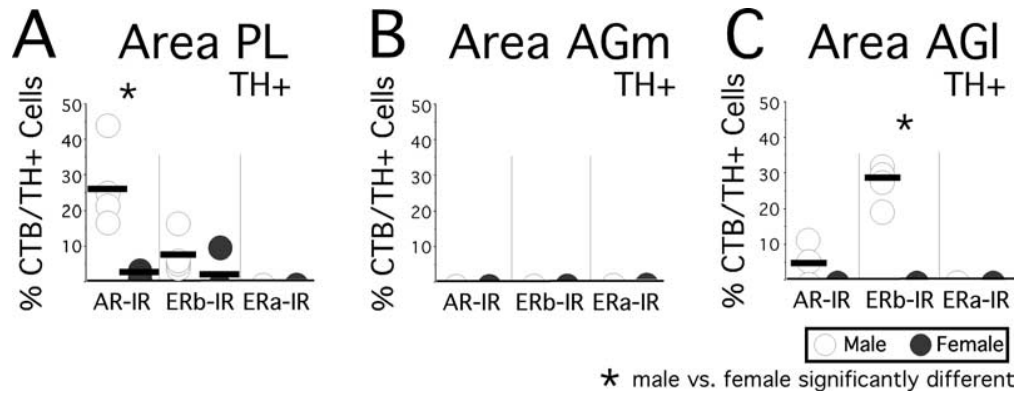

Figure 7. Scatter plot showing the percentages of all visible cells retrogradely labeled by cholera toxin and immunoreactive for tyrosine hydroxylase $(\mathrm{CTB} / \mathrm{TH}+)$ that were also immunoreactive for intracellular androgen receptor (AR-IR), estrogen receptor $\beta$ (ER $\beta$-IR), or estrogen receptor $\alpha$ (ER $\alpha$-IR). The data collected in the four male (open circles) and four female (black circles) subjects are shown separately for cells back-labeled by injection sites in area $\mathrm{PL}(\boldsymbol{A})$, area $\mathrm{AGm}(\boldsymbol{B})$, and area $\mathrm{AGI}(\boldsymbol{C})$. Group means are marked by horizontal black bars. Asterisks identify cases in which Mann-Whitney/Wilcoxon rank sum tests identified significant differences in the proportions of retrogradely labeled, hormone receptor-immunoreactive, TH-immunopositive cells between males and females.
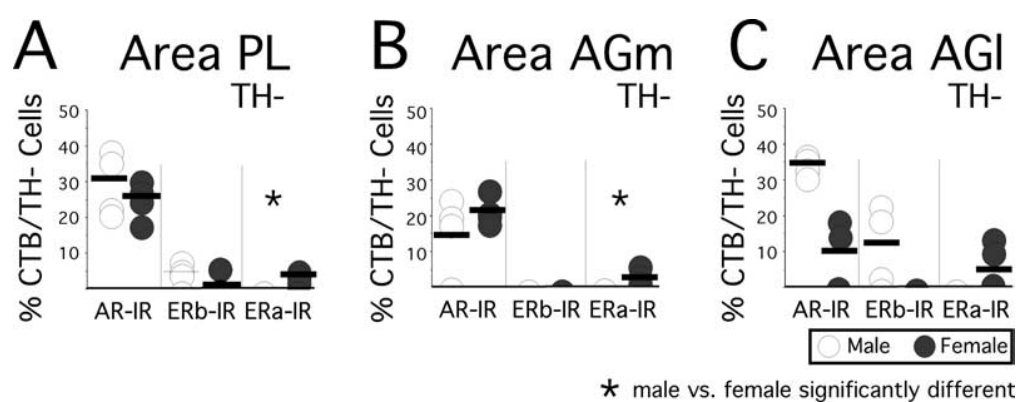

Figure 8. A-C, Scatter plot showing the percentages of all visible cells retrogradely labeled by cholera toxin that were immunonegative for tyrosine hydroxylase (CTB/TH - ) and that were also immunoreactive for intracellular androgen receptor (AR-IR), estrogen receptor $\beta$ (ER $\beta$-IR), or estrogen receptor $\alpha$ (ER $\alpha-\mathrm{IR})$. The data collected in the four male (open circles) and four female (black circles) subjects are shown separately for cells back-labeled by injection sites in area $\mathrm{PL}(\boldsymbol{A})$, area $\mathrm{AGm}(\boldsymbol{B})$, and area $\mathrm{AGI}(\boldsymbol{C})$. Group means are marked by horizontal black bars. Asterisks identify cases in which Mann-Whitney/Wilcoxon rank sum tests identified significant differences in the proportions of retrogradely labeled, hormone receptor-immunoreactive, THimmunonegative cells between males and females.

Sherwin, 2007), or hypopituitarism (Miller et al., 2006), identify androgen modulation of cortical information processing in females as an important, clinically relevant area to pursue and clarify. This could include behavioral and biochemical assessment of the modest AR-IR, DAergic medial prefrontal projections identified in this study in female rats challenged with nonaromatizable androgens.

Subsets of non-DAergic neurons that were hormone receptorimmunoreactive were also found. The consequences of genomic actions at these sites are difficult to predict because of a limited understanding of exact functional roles for non-DAergic mesocortical afferents. However, that substantial projections to all three cortical regions in males and females were AR-IR could indicate androgen-mediated genomic influence over more canonical, cortical-, and sex-wide sorts of operations, e.g., modulation of signal-to-noise. In contrast, that non-DAergic cells were immunoreactive for $\mathrm{ER} \beta$ but not $\mathrm{ER} \alpha$ in males, and immunoreactive for $\mathrm{ER} \alpha$ but not $\mathrm{ER} \beta$ in females suggests that estrogenmediated genomic actions may be sex-specific. The opposing actions of estrogen stimulation at $\mathrm{ER} \alpha$ vs $\mathrm{ER} \beta$ sites demonstrated in other systems (Nilsen et al., 2000) suggest that even the relatively small populations of ER $\beta$-IR versus $E R \alpha$-IR non-DAergic neurons found in males versus females could contribute to sex differences in mesocortical function or physiology.

\section{Sex differences in neurochemical} makeup of mesocortical pathways

In rats, DAergic neurons are shown to comprise only approximately one-third of meso-prefrontal projections (Swanson, 1982; Deutch et al., 1991; Carr and Sesack, 2000; Margolis et al., 2006). This study found similarly low proportions of constituent DAergic cells for the three cortical pathways investigated here, but only in males; in females, the proportions of constituent DAergic cells were significantly higher. Because rostrocaudal locations of labeling were similar, these sex-specific proportions are probably unrelated to the anteroposterior differences in DA/ non-DA neuron ratios known for rat VTA (Swanson, 1982; German and Manaye, 1993; Olson et al., 2005). The higher values in females also do not contradict the literature in which all quantitative studies to date have used male subjects exclusively.

Differences in the proportions of DAergic accumbally projecting VTA neurons have been correlated with certain molecular, cellular, and behavioral responses of these pathways to drugs of abuse (Ikemoto et al., 1997; Zangen et al., 2002; Bolaños et al., 2003; Olson et al., 2005). Accordingly, the sex-specific DA/non-DA ratios identified here for mesocortical pathways may also have functional correlates. For example, given that prefrontal functions depend on DA levels falling within narrow limits (Murphy et al., 1996; Verma and Moghaddam, 1996; Zahrt et al., 1997), it is possible that sex differences in DA pathway content could presage different operational modes for mesoprefrontal systems in males and females. The applicability of contemporary models of meso-prefrontal function to females also comes into question, because the data regarding DA levels and their uniquely extended extracellular lifetimes on which many are based are derived primarily to exclusively from analyses in males (Durstewitz et al., 2000; Durstewitz and Seamans, 2002). Finally, this significant pathway difference may also warrant reconsideration of the neurobiology that may be relevant for sex differences seen in certain pathological states. For example, it is possible that the greater vulnerability of female rats to prefrontal-impairing effects of stress (Shansky et al., 2004, 2006; Dalla et al., 2008) could reflect stress actions on larger cohorts of afferents and subsequently greater impact on prefrontal DA levels in this sex. That quantitative sex differences in defined types of mesocortical neurons could also result from early, organizational hormone effects, e.g., effects on cell survival, may also be important for developmental disorders like schizophrenia, autism, and dyslexia, because it suggests a timeline for gonadal hormone-shaping of potentially functionally critical parameters of the mesocortical DA system that align with prenatal/obstetric complications, which are strong predictors of aspects of these disorders, including the severity of prefrontal symptoms (Geschwind and Galaburda, 1985; O'Callaghan et al., 1990; Lane et al., 1996; Ohara et al., 2003). At the least, the current findings suggest that full under- 
standing of mesocortical/meso-prefrontal systems and their roles in health and disease will ultimately require knowledge about the sensitivities of their DA and non-DAergic components to both organizational and activational hormone effects and cataloguing of their sex differences.

\section{References}

Akhondzadeh S, Rezaei F, Larijani B, Nejatisafa AA, Kashani L, Abbasi SH (2006) Correlation between testosterone, gonadotropins and prolactin and severity of negative symptoms in male patients with chronic schizophrenia. Schizophr Res 84:405-410.

Aldes LD (1988) Thalamic connectivity of rat somatic motor cortex. Brain Res Bull 20:333-348.

Aleman A, Bronk E, Kessels RP, Koppeschaar HP, van Honk J (2004) A single administration of testosterone improves visuospatial ability in young women. Psychoneuroendocrinology 29:612-617.

Alexander GM, Swerdloff RS, Wang C, Davidson T, McDonald V, Steiner B, Hines M (1998) Androgen-behavior correlations in hypogonadal men and eugonadal men. II. Cognitive abilities. Horm Behav 33:85-94.

Aubele T, Kaufman R, Montalmant F, Kritzer MF (2008) Effects of gonadectomy and hormone replacement on a spontaneous novel object recognition task in adult male rats. Horm Behav 54:244-252.

Bachevalier J, Hagger C (1991) Sex differences in the development of learning abilities in primates. Psychoneuroendocrinology 16:177-188.

Bolaños CA, Perrotti LI, Edwards S, Eisch AJ, Barrot M, Olson VG, Russell DS, Neve RL, Nestler EJ (2003) Phospholipase Cgamma in distinct regions of the ventral tegmental area differentially modulates mood-related behaviors. J Neurosci 23:7569-7576.

Carr DB, Sesack SR (2000) GABA-containing neurons in the rat ventral tegmental area project to the prefrontal cortex. Synapse 38:114-123.

Ceccarelli I, Scaramuzzino A, Aloisi AM (2001) Effects of gonadal hormones and persistent pain on non-spatial working memory in male and female rats. Behav Brain Res 123:65-76.

Cherrier MM, Craft S, Matsumoto AH (2003) Cognitive changes associated with supplementation of testosterone or dihydrotestosterone in mildly hypogonadal men: a preliminary report. J Androl 24:568-576.

Clark AS, Goldman-Rakic PS (1989) Gonadal hormones influence the emergence of cortical function in nonhuman primates. Behav Neurosci 103:1287-1295.

Condé F, Audinat E, Maire-Lepoivre E, Crépel F (1990) Afferent connections of the medial frontal cortex of the rat. A study using retrograde transport of fluorescent dyes. I. Thalamic afferents. Brain Res Bull 24:341-354.

Creutz LM, Kritzer MF (2002) Estrogen receptor-beta immunoreactivity in the midbrain of adult rats: regional, subregional, and cellular localization in the A10, A9, and A8 dopamine cell groups. J Comp Neurol 446:288-300.

Creutz LM, Kritzer MF (2004) Mesostriatal and mesolimbic projections of midbrain neurons immunoreactive for estrogen receptor beta or androgen receptors in rats. J Comp Neurol 476:348-362.

Dalla C, Antoniou K, Kokras N, Drossopoulou G, Papathanasiou G, Bekris S, Daskas S, Papadopoulou-Daifoti Z (2008) Sex differences in the effects of two stress paradigms on dopaminergic neurotransmission. Physiol Behav 93:595-605.

Daniel JM, Winsauer PJ, Moerschbaecher JM (2003) Castration in rats impairs performance during acquisition of a working memory task and exacerbates deficits in working memory produced by scopolamine and mecamylamine. Psychopharmacology (Berl) 170:294-300.

Datiche F, Cattarelli M (1996) Catecholamine innervation of the piriform cortex: a tracing and immunohistochemical study in the rat. Brain Res 710:69-78.

Deutch AY, Lee MC, Gillham MH, Cameron DA, Goldstein M, Iadarola MJ (1991) Stress selectively increases fos protein in dopamine neurons innervating the prefrontal cortex. Cereb Cortex 1:273-292.

Diamond A (1985) Development of the ability to use recall to guide action, as indicated by infants' performance on AB. Child Dev 56:868-883.

Donoghue JP, Parham C (1983) Afferent connections of the lateral agranular field of the rat motor cortex. J Comp Neurol 217:390-404.

Donoghue JP, Wise SP (1982) The motor cortex of the rat: cytoarchitecture and microstimulation mapping. J Comp Neurol 212:76-88.

Durstewitz D, Seamans JK (2002) The computational role of dopamine D1 receptors in working memory. Neural Netw 15:561-572.
Durstewitz D, Seamans JK, Sejnowski TJ (2000) Dopamine-mediated stabilization of delay-period activity in a network model of prefrontal cortex. J Neurophysiol 83:1733-1750.

Edinger KL, Lee B, Frye CA (2004) Mnemonic effects of testosterone and its 5alpha-reduced metabolites in the conditioned fear and inhibitory avoidance tasks. Pharmacol Biochem Behav 78:559-568.

Einon D (1980) Spatial memory and response strategies in rats: age, sex and rearing differences in performance. Q J Exp Psychol 32:473-489.

Frye CA, Edinger KL, Seliga AM, Wawrzycki JM (2004) 5alpha-reduced androgens may have actions in the hippocampus to enhance cognitive performance of male rats. Psychoneuroendocrinology 29:1019-1027.

German DC, Manaye KF (1993) Midbrain dopaminergic neurons (nuclei A8, A9, and A10): three-dimensional reconstruction in the rat. J Comp Neurol 331:297-309.

Geschwind N, Galaburda AM (1985) Cerebral lateralization. Biological mechanisms, associations, and pathology: I. A hypothesis and a program for research. Arch Neurol 42:428-459.

Gibbs RB (2005) Testosterone and estradiol produce different effects on cognitive performance in male rats. Horm Behav 48:268-277.

Gibbs RB, Gabor R (2003) Estrogen and cognition: applying preclinical findings to clinical perspectives. J Neurosci Res 74:637-643.

Goodman R, Stevenson J (1989) A twin study of hyperactivity-I. An examination of hyperactivity scores and categories derived from Rutter teacher and parent questionnaires. J Child Psychol Psychiatry 30:671-689.

Gouchie C, Kimura D (1991) The relationship between testosterone levels and cognitive ability patterns. Psychoneuroendocrinology 16:323-334.

Goyal RO, Sagar R, Ammini AC, Khurana ML, Alias AG (2004) Negative correlation between negative symptoms of schizophrenia and testosterone levels. Ann N Y Acad Sci 1032:291-294.

Guillery RW (2002) On counting and counting errors. J Comp Neurol 447:1-7.

Hampson E (1990) Variations in sex-related cognitive abilities across the menstrual cycle. Brain Cogn 14:26-43.

Heidbreder CA, Groenewegen HJ (2003) The medial prefrontal cortex in the rat: evidence for a dorso-ventral distinction based upon functional and anatomical characteristics. Neurosci Biobehav Rev 27:555-579.

Hicks RR, Huerta MF (1991) Differential thalamic connectivity of rostral and caudal parts of cortical area Fr2 in rats. Brain Res 568:325-329.

Huber TJ, Tettenborn C, Leifke E, Emrich HM (2005) Sex hormones in psychotic men. Psychoneuroendocrinology 30:111-114.

Ikemoto S, Murphy JM, McBride WJ (1997) Self-infusion of GABA(A) antagonists directly into the ventral tegmental area and adjacent regions. Behav Neurosci 111:369-380.

Janowsky JS (2006) Thinking with your gonads: testosterone and cognition. Trends Cogn Sci 10:77-82.

Kessler J, Markowitsch HJ (1981) Delayed-alternation performance after kainic acid lesions of the thalamic mediodorsal nucleus and the ventral tegmental area in the rat. Behav Brain Res 3:125-130.

Kritzer MF (1997) Selective colocalization of immunoreactivity for intracellular gonadal hormone receptors and tyrosine hydroxylase in the ventral tegmental area, substantia nigra, and retrorubral fields in the rat. J Comp Neurol 379:247-260.

Kritzer MF (2002) Regional, laminar, and cellular distribution of immunoreactivity for ER alpha and ER beta in the cerebral cortex of hormonally intact, adult male and female rats. Cereb Cortex 12:116-128.

Kritzer MF (2003) Long-term gonadectomy affects the density of tyrosine hydroxylase- but not dopamine-beta-hydroxylase-, choline acetyltransferase- or serotonin-immunoreactive axons in the medial prefrontal cortices of adult male rats. Cereb Cortex 13:282-296.

Kritzer MF, McLaughlin PJ, Smirlis T, Robinson JK (2001) Gonadectomy impairs T-maze acquisition in adult male rats. Horm Behav 39:167-174.

Kritzer MF, Brewer A, Montalmant F, Davenport M, Robinson JK (2007) Effects of gonadectomy on performance in operant tasks measuring prefrontal cortical function in adult male rats. Horm Behav 51:183-194.

Lane A, Colgan K, Moynihan F, Burke T, Waddington JL, Larkin C, O'Callaghan E (1996) Schizophrenia and neurological soft signs: gender differences in clinical correlates and antecedent factors. Psychiatry Res 64:105-114.

Leviton A, Bellinger D, Allred E (1993) The Boston Teacher Questionnaire. 3. A reassessment. J Child Neurol 8:64-72.

Lindvall O, Björklund A, Divac I (1978) Organization of catecholamine neurons projecting to the frontal cortex in the rat. Brain Res 142:1-24. 
Loughlin SE, Fallon JH (1984) Substantia nigra and ventral tegmental area projections to cortex: topography and collateralization. Neuroscience 11:425-435.

Margolis EB, Lock H, Chefer VI, Shippenberg TS, Hjelmstad GO, Fields HL (2006) Kappa opioids selectively control dopaminergic neurons projecting to the prefrontal cortex. Proc Natl Acad Sci U S A 103:2938-2942.

Miller KK, Biller BM, Beauregard C, Lipman JG, Jones J, Schoenfeld D, Sherman JC, Swearingen B, Loeffler J, Klibanski A (2006) Effects of testosterone replacement in androgen-deficient women with hypopituitarism: a randomized, double-blind, placebo-controlled study. J Clin Endocrinol Metab 91:1683-1690.

Moore RY, Bloom FE (1978) Central catecholamine neuron systems: anatomy and physiology of the dopamine systems. Annu Rev Neurosci 1:129-169.

Murphy BL, Arnsten AF, Goldman-Rakic PS, Roth RH (1996) Increased dopamine turnover in the prefrontal cortex impairs spatial working memory performance in rats and monkeys. Proc Natl Acad Sci U S A 93:1325-1329.

Nilsen J, Mor G, Naftolin F (2000) Estrogen-regulated developmental neuronal apoptosis is determined by estrogen receptor subtype and the Fas/ Fas ligand system. J Neurobiol 43:64-78.

O'Callaghan E, Larkin C, Waddington JL (1990) Obstetric complications in schizophrenia and the validity of maternal recall. Psychol Med 20:89-94.

Ohara PT, Granato A, Moallem TM, Wang BR, Tillet Y, Jasmin L (2003) Dopaminergic input to GABAergic neurons in the rostral agranular insular cortex of the rat. J Neurocytol 32:131-141.

Olson VG, Zabetian CP, Bolanos CA, Edwards S, Barrot M, Eisch AJ, Hughes T, Self DW, Neve RL, Nestler EJ (2005) Regulation of drug reward by cAMP response element-binding protein: evidence for two functionally distinct subregions of the ventral tegmental area. J Neurosci 25:5553-5562.

Overman WH, Bachevalier J, Schuhmann E, Ryan P (1996) Cognitive gender differences in very young children parallel biologically based cognitive gender differences in monkeys. Behav Neurosci 110:673-684.

Paxinos G, Watson C (1998) The rat brain in stereotoxic coordinates, 4th Ed. New York: Academic.

Phillipson OT (1979) The cytoarchitecture of the interfascicular nucleus and ventral tegmental area of Tsai in the rat. J Comp Neurol 187:85-98.

Postma A, Meyer G, Tuiten A, van Honk J, Kessels RP, Thijssen J (2000) Effects of testosterone administration on selective aspects of objectlocation memory in healthy young women. Psychoneuroendocrinology 25:563-575.

Puts DA, McDaniel MA, Jordan CL, Breedlove SM (2008) Spatial ability and prenatal androgens: meta-analyses of congenital adrenal hyperplasia and digit ratio (2D:4D) studies. Arch Sex Behav 37:100-111.

Reep RL, Corwin JV (1999) Topographic organization of the striatal and thalamic connections of rat medial agranular cortex. Brain Res 841:43-52.

Reep RL, Goodwin GS, Corwin JV (1990) Topographic organization in the corticocortical connections of medial agranular cortex in rats. J Comp Neurol 294:262-280.

Salminen E, Portin R, Korpela J, Backman H, Parvinen LM, Helenius H, Nurmi M (2003) Androgen deprivation and cognition in prostate cancer. Br J Cancer 89:971-976.

Salminen EK, Portin RI, Koskinen AI, Helenius HY, Nurmi MJ (2005) Estradiol and cognition during androgen deprivation in men with prostate carcinoma. Cancer 103:1381-1387.

Schattmann L, Sherwin BB (2007) Testosterone levels and cognitive functioning in women with polycystic ovary syndrome and in healthy young women. Horm Behav 51:587-596.

Seeman MV, Lang M (1990) The role of estrogens in schizophrenia gender differences. Schizophr Bull 16:185-194.

Shansky RM, Glavis-Bloom C, Lerman D, McRae P, Benson C, Miller K, Cosand L, Horvath TL, Arnsten AF (2004) Estrogen mediates sex differences in stress-induced prefrontal cortex dysfunction. Mol Psychiatry 9:531-538.

Shansky RM, Rubinow K, Brennan A, Arnsten AF (2006) The effects of sex and hormonal status on restraint-stress-induced working memory impairment. Behav Brain Funct 2:8.

Shirayama Y, Hashimoto K, Suzuki Y, Higuchi T (2002) Correlation of plasma neurosteroid levels to the severity of negative symptoms in male patients with schizophrenia. Schizophr Res 58:69-74.

Stewart J, Rajabi H (1994) Estradiol derived from testosterone in prenatal life affects the development of catecholamine systems in the frontal cortex in the male rat. Brain Res 646:157-160.

Swanson LW (1982) The projections of the ventral tegmental area and adjacent regions: a combined fluorescent retrograde tracer and immunofluorescence study in the rat. Brain Res Bull 9:321-353.

Taherianfard M, Shariaty M (2004) Evaluation of serum steroid hormones in schizophrenic patients. Indian J Med Sci 58:3-9.

Tees RC, Midgley G, Nesbit JC (1981) The effect of early visual experience on spatial maze learning in rats. Dev Psychobiol 14:425-438.

Van Eden CG, Uylings HB (1985) Cytoarchitectonic development of the prefrontal cortex in the rat. J Comp Neurol 241:253-267.

van Haaren F, van Hest A, Heinsbroek RP (1990) Behavioral differences between male and female rats: effects of gonadal hormones on learning and memory. Neurosci Biobehav Rev 14:23-33.

Verma A, Moghaddam B (1996) NMDA receptor antagonists impair prefrontal cortex function as assessed via spatial delayed alternation performance in rats: modulation by dopamine. J Neurosci 16:373-379.

Zahrt J, Taylor JR, Mathew RG, Arnsten AF (1997) Supranormal stimulation of D1 dopamine receptors in the rodent prefrontal cortex impairs spatial working memory performance. J Neurosci 17:8528-8535.

Zangen A, Ikemoto S, Zadina JE, Wise RA (2002) Rewarding and psychomotor stimulant effects of endomorphin-1: anteroposterior differences within the ventral tegmental area and lack of effect in nucleus accumbens. J Neurosci 22:7225-7233. 